\title{
Adaptation and validation of the Bristol scale stool form translated into the Spanish language among health professionals and patients
}

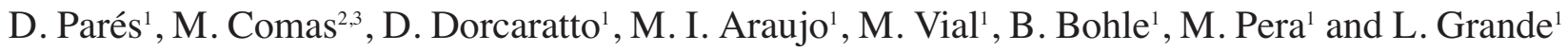 \\ ${ }^{I}$ Colorectal Surgery Unit. Department of Surgery. Hospital Universitari del Mar. Barcelona, Spain. ${ }^{2}$ Department of \\ Evaluation and Clinical Epidemiology. Hospital Universitari del Mar. Barcelona, Spain. ${ }^{3}$ CIBER de Epidemiología y \\ Salud Pública (CIBERESP). Spain
}

\begin{abstract}
Background: stool type represents an important semiologic part of medical interviews. The Bristol Scale Stool Form is a clinical tool to evaluate stool consistency and form. The aim of this study was to translate and adapt the Bristol Scale Stool Form into Spanish. Differences in validation results between health professionals and patients surveyed were also evaluated.

Methods: the study population included 79 physicians, 79 nurses, and 78 patients. Subjects were invited to match a randomly selected text defining one of the seven stool types in the scale with one of seven drawings described originally. A random selection of samples was offered for re-test reliability.

Results: the overall Kappa index was 0.708. Thirty-two subjects repeated the test for a test-retest assessment in a mean interval of 7.76 days, and the percentage concordance between definition and image was $84.4 \%$ with a Kappa index of 0.816 . There were no differences in the validation study between physicians, nurses, and patients.

Conclusions: this study has shown that the Spanish version of the Bristol Scale Stool Form is reliable for use as a tool to evaluate stool consistency and form.
\end{abstract}

Key words: Bristol scale stool form. Stool consistency. Spanish version. Validation study.

Parés D, Comas M, Dorcaratto DI, Araujo MI, Vial M, Bohle B, Pera M, Grande L. Adaptation and validation of the bristol scale stool form as translated into the spanish language among health professionals and patients. Rev Esp Enferm Dig 2009; 101: 312-316.

Received: 22-01-09.

Accepted: 24-02-09.

Correspondence: David Parés. Unidad de Cirugía Colorrectal. Departamento de Cirugía. Hospital Universitari del Mar. Passeig Maritim 25-29. 08003 Barcelona, Spain.e-mail: Dpares@imas.imim.es

\section{INTRODUCTION}

Stool appearance and consistency represent an important semiologic part of the clinical approach to the patient with gastrointestinal disorders (1). A patient's description of his or her own stools is important, as well as the description provided by attending physicians or nurses. Also, it is well known that changes in stool consistency produced by diets or drugs have been used as a first medical approach for fecal incontinence or severe constipation (2).

However, it is very difficult to obtain an accurate description of stool appearance and consistency, and therefore some descriptive visual scales have been proposed (3). Heaton and Thompson (4) presented the most widely used seven-point scale, which was called the Bristol Scale Stool Form. This scale was validated in healthy control subjects and in patients with gastrointestinal disorders as being correlated with complete gut transit time, and its efficacy has been demonstrated clinically and for research purposes $(5,6)$. To ensure that patients can precisely describe their own fecal pattern a diagram of stool type has been added to the text definitions for the seven stool types included in the scale (7).

The Spanish language constitutes the second most commonly used language in Western countries and in Europe. Data from the US Census indicate that 32.8 million Hispanics of diverse geographical origins reside in the USA (8). Spanish remains the only or preferred language for many of them, and therefore it is essential that appropriate Spanish-language clinical scales are available. To our knowledge no Spanish adaptation and validation of the Bristol Scale Stool Form had been performed thus far.

The aim of this study was to translate and adapt the Bristol Scale Stool Form into the Spanish language. Furthermore, differences in validation results between health professionals and patients surveyed were also evaluated. 


\section{MATERIAL AND METHODS}

Permission was obtained for the use of the original Bristol Scale Stool Form from its author, and the study was approved by the Ethical Committee of our hospital (Reference 2007/2869). This is a descriptive and visual seven-point scale which describes 7 stool types. The description differentiates: type 1: separate hard lumps, like nuts; type 2: sausage shaped but lumpy; type 3: like a sausage or snake but with cracks on its surface; type 4: like a sausage or snake, smooth and soft; type 5: soft blobs with clear-cut edges; type 6: fluffy pieces with ragged edges, a mushy stool; and finally type 7: watery, no solid pieces. This description is accompanied by a bowel record with diagrams for all types of stools (7).

\section{Translation and cultural adaptation}

The translation into Spanish was performed by 2 specialists in functional digestive disorders with a perfect knowledge of the English and Spanish languages. Once translated some descriptions were modified for adaptation to the Spanish language and culture. Then the scale was back-translated from Spanish into English by two native bilingual specialists from the United Kingdom. Following author consensus, the Spanish version was administered to 9 subjects ( 3 physicians, 3 nurses, and 3 patients) to determine possible comprehension problems. The final version, called "Escala de Bristol de Forma y Consistencia de las Heces", was used for this study (Fig. 1).

\section{Study design}

The study population included 158 healthcare professionals in a hospital setting (79 physicians and 79 nurses), and 78 patients over 18 years of age. All surveys were performed between August 2007 and November 2007 in one hospital. Subjects were presented 7 drawings depicting different stool types. Then, they were invited to match a randomly selected text defining one of the seven types of stools in the translated scale with one of the seven drawings published originally. Additionally, a random selection of $10 \%$ of subjects from each group (physicians, nurses and patients) was instructed to repeat the survey after 15 days in order to assess test-retest reliability.

\section{Statistical analysis}

The main endpoint of the study was the percentage of concordance between text definitions of stool type and the appropriate drawing (Fig. 1). A sample size of 73 subjects in each surveyed group was calculated to estimate 95\% concordance with 5\% precision and 5\% significance.

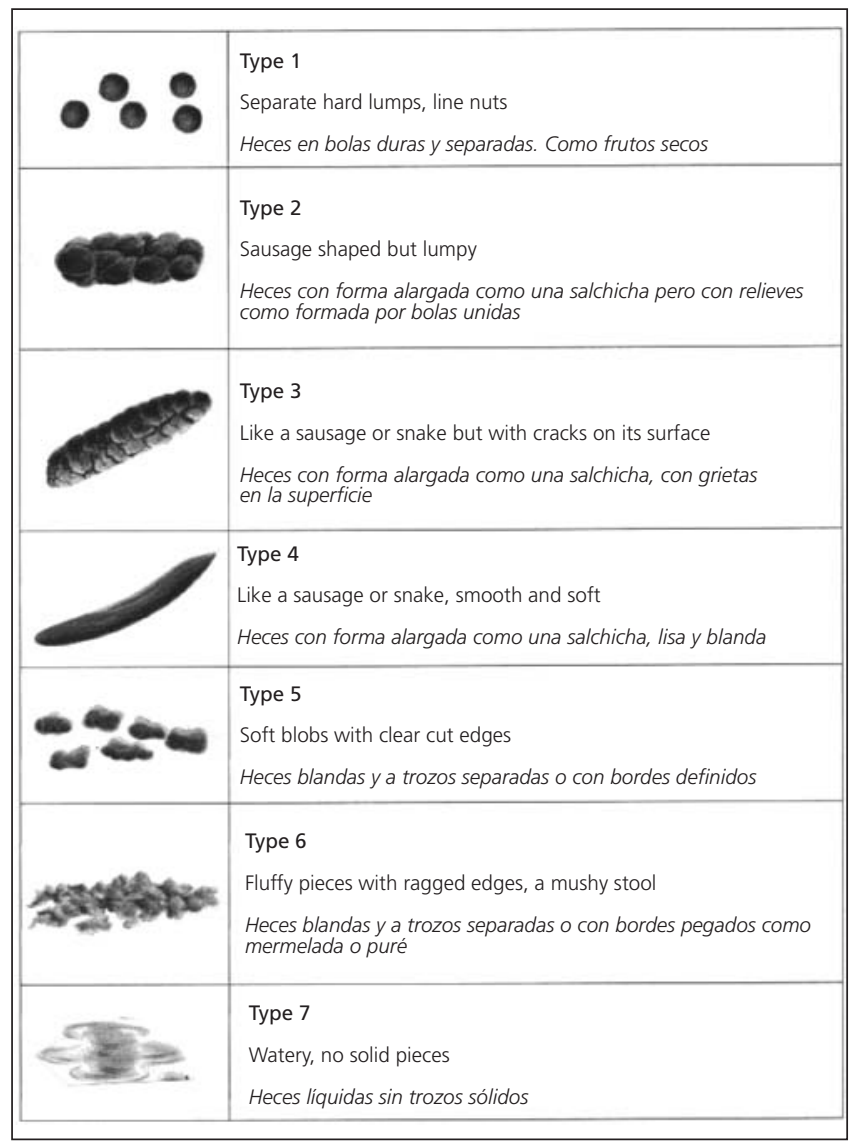

Fig. 1. Bristol Scale Stool Form in English and Spanish version.

Variables were described as mean and standard deviation for quantitative variables, and by absolute numbers and percentages for qualitative variables. Internal reliability was analyzed by means of percentage concordance and Kappa index. Comparative analyses were performed using Fisher's exact test for percentage concordance, and Fleiss' method for Kappa values (9). Test-retest reliability or temporal stability (scale assessment repeated within 15 days during which no change was expected to occur) was also evaluated through percentage concordance and Kappa index between responses. A bilateral $\mathrm{p}$ value less than 0.05 was considered statistically significant.

\section{RESULTS}

Table I lists sample characteristics. There were differences in age and gender distribution related to professional profile. Most patients (76.6\%) had no university degree.

Table II shows the matching or concordance results (text definition and image) for the validation test in all groups of subjects. Table III shows concordance among subjects surveyed for all types of stools. The highest percentage concordance was $91.5 \%$ for stool type 7 , and stool type 5 had the lowest rate $(43.8 \%)$. 
Table I. Characteristics of the sample participating in the validation study of the Bristol Scale Stool Form

\begin{tabular}{lccc}
\hline & $\begin{array}{c}\text { Physicians } \\
n=79\end{array}$ & $\begin{array}{c}\text { Nurses } \\
n=79\end{array}$ & $\begin{array}{c}\text { Patients } \\
n=78\end{array}$ \\
\hline Age (years)* & $33.0(9.3)$ & $35.6(11.4)$ & $55.7(18.0)$ \\
Gender (\%) & & & \\
$\quad$ Male & $39(49.4 \%)$ & $6(7.6 \%)$ & $34(43.6 \%)$ \\
$\quad$ Female & $40(51.6 \%)$ & $73(92.4 \%)$ & $44(56.4 \%)$ \\
Education level (\%) & & & $60(76.6 \%)$ \\
$\quad$ No university degree & & $18(23.4 \%)$ \\
University degree & & \\
Primary disease (\%) & & & \\
$\quad$ Gastrointestinal & & & $36(46.8 \%)$ \\
Other & & & \\
\hline
\end{tabular}

*Mean (standard deviation).

Table II. Matching results between definitions and images in the overall series

\begin{tabular}{ccccccccc}
\hline \multicolumn{7}{c}{ Images } \\
\hline Definition & 1 & 2 & 3 & 4 & 5 & 6 & 7 & Total \\
\hline 1 & 23 & 1 & 4 & 0 & 4 & 2 & 0 & 34 \\
2 & 0 & 23 & 8 & 1 & 0 & 0 & 0 & 32 \\
3 & 0 & 3 & 20 & 4 & 1 & 0 & 0 & 28 \\
4 & 0 & 0 & 1 & 40 & 1 & 2 & 0 & 44 \\
5 & 7 & 4 & 1 & 1 & 16 & 4 & 1 & 34 \\
6 & 0 & 0 & 3 & 1 & 2 & 25 & 0 & 31 \\
7 & 0 & 0 & 0 & 0 & 2 & 1 & 30 & 33 \\
\hline Total & 30 & 31 & 37 & 47 & 26 & 34 & 31 & 236
\end{tabular}

Table III. Concordance (in percentage) between definitions and images in relation to type of stool and subjects surveyed

\begin{tabular}{ccccc}
\hline & $\begin{array}{c}\text { Physicians } \\
n=79\end{array}$ & $\begin{array}{c}\text { Nurses } \\
n=79\end{array}$ & $\begin{array}{c}\text { Patients } \\
n=78\end{array}$ & $\begin{array}{c}\text { Overall } \\
n=236\end{array}$ \\
\hline Type of stool & & & & \\
\hline 1 & $81.8 \%$ & $58.3 \%$ & $63.6 \%$ & $67.9 \%$ \\
2 & $100 \%$ & $70 \%$ & $50 \%$ & $73.3 \%$ \\
3 & $85.7 \%$ & $60 \%$ & $72.7 \%$ & $72.8 \%$ \\
4 & $93.8 \%$ & $88.2 \%$ & $90.9 \%$ & $90.9 \%$ \\
5 & $71.4 \%$ & $20 \%$ & $40 \%$ & $43.8 \%$ \\
6 & $90.9 \%$ & $100 \%$ & $50 \%$ & $80.3 \%$ \\
7 & $100 \%$ & $90 \%$ & $84.6 \%$ & $91.5 \%$ \\
\hline
\end{tabular}

The overall Kappa index was 0.708 , and the summary of concordance for this index in each of the groups is included in table IV.

Table $\mathrm{V}$ reports the results of validation in the patient group according to patient characteristics. There were no statistical differences in percentage concordance according to age and primary disease. However, concordance and Kappa index were statistically significantly lower in the subgroup of patients without university education.
Table IV. Concordance results and correlation in the overall study

\begin{tabular}{lcccc}
\hline & Concordance & $p^{*}$ & Kappa & $p^{* *}$ \\
\hline Overall & $75 \%$ & & 0.708 & \\
\hline Group & & & & \\
Physicians & $88.6 \%$ & & 0.866 & \\
Nurses & $70.9 \%$ & & 0.657 & \\
Patients & $65.4 \%$ & 0.002 & 0.596 & $<0.001$ \\
\hline
\end{tabular}

Table V. Concordance results and correlation in the patients group

\begin{tabular}{lcccc}
\hline & Concordance & $p^{*}$ & Kappa & $p^{* *}$ \\
\hline Age group & & & & \\
$\quad<60$ years & $69 \%$ & & 0.632 & \\
$\geq 60$ years & $61.1 \%$ & 0.484 & 0.542 & 0.473 \\
\hline $\begin{array}{l}\text { Education level } \\
\quad \text { University degree }\end{array}$ & $83.3 \%$ & & & \\
$\quad$ No university degree & $59.3 \%$ & 0.09 & 0.799 & \\
\hline Primary disease & & & & \\
$\quad$ Gastrointestinal & $66.7 \%$ & & 0.607 & \\
$\quad$ Other & $63.9 \%$ & 0.816 & 0.577 & 0.809 \\
\hline${ }^{*}$ Chi-squared test; **Fleiss method. & & & \\
\end{tabular}

Thirty-two subjects ( 9 physicians, 14 nurses and 9 patients) repeated the test for the test-retest assessment within a mean interval of 7.76 days (standard deviation of 5.30, range 2-15). Overall percentage concordance between definition and image was $84.4 \%$ with a Kappa index of 0.816 (95\% CI: 0.669-0.962).

\section{DISCUSSION}

In clinical practice achieving changes in stool consistency is of paramount importance in the management of some digestive functional diseases (10). Therefore, an evaluation of the appearance and consistency of stools represents an important semiologic part of the clinical approach to the patient with gastrointestinal disorders $(11,12)$. The Bristol Scale Stool Form was developed to improve this issue and in the present study has demonstrated that the proposed Spanish version is suitable for use in both clinical practice and research.

The Bristol Scale Stool Form is based on a text definition and a drawing of every type of feces. In fact, there is no information in the literature, but in our clinical practice we have observed that patients use both methods to describe the bowel movements that "they usually have". Consequently, when we decided to perform this study, the troublesome issue was to decide what our validation should consist of and, therefore, what the gold standard 
could be. Finally the study was designed considering the drawing of stools as the gold standard.

In this study we have demonstrated that the proposed Spanish version can be used as a scale to measure stool consistency and form because of an overall concordance of $75 \%$ and a Kappa index of 0.708 . Test-retest assessment also demonstrated the high reliability of this instrument. However, some interesting lessons were learned from the study. Although it was impossible to use identical sample characteristics, the validation was satisfactory in all subgroups of the sample. Interesting$1 y$, the results were better in subjects with universitylevel education. Thus, the group of older patients without university education had the worst concordance and worst Kappa index results. It should be pointed out that a great effort could be necessary during the clinical interview of these groups of patients to obtain precise and reliable information.

The authors were particularly interested in knowing whether illustrated stools matched text descriptions. The special design of the study with one text definition for one stool image allowed this issue to be studied in depth. Surprisingly, among physicians, patients, and specially nurses we noted that stool type 5 (Soft blobs with clearcut edges) was particularly difficult to differentiate from type 1 (Table II). Further investigations are warranted to confirm these results and to evaluate whether a simplification of this scale might be necessary.

We have to take into account that the study was carried out in the most demanding way. We assumed that if subjects were provided with all 7 descriptions and 7 diagrams of stool types simultaneously, they would match the clearest descriptions (for example, stool types 4 and 7) and then perform an elimination process with the remaining types. Therefore, to avoid a selection bias, we decided to use only one text definition for any surveyed subject. Consequently, each individual had one possibility only in the matching process, with text descriptions being given one by one to match with one of the seven illustrated stool types.

The Bristol Scale Stool Form is a good tool to obtain a description of stools by the general population and patients. In an excellent study, it has been demonstrated that the Bristol scale correlates very well with whole gut transit time and fecal output (5). However, the most useful issue is the fact that untrained people can assess the form of their stools with reasonable accuracy with this self-assessed stool form (13). Previous studies have also demonstrated the usefulness of this scale to evaluate patients with irritable bowel syndrome, to accurately assess changes in stool by drug administration, or indeed to know stool forms in the community $(10,13,14)$. In a recent description of a very comprehensive fecal incontinence questionnaire, the Bristol Scale Stool Form was included for its clinical relevance as a validated method for assessing stool form in the interview (12). Heaton et al. (13) also suggested that if data on stool form were col- lected in non-different populations they could be used to test hypotheses that slow transit predisposes to Western diseases such as bowel cancer, diverticular disease, gallstones, and breast cancer. Interestingly, the Bristol Scale Stool Form has been used in only a few studies in the community, and in some cases using a translated but nonvalidated version $(6,15-23)$. Thus, the main endpoint of the present study was to perform not only a Spanish translation of the scale, but also to test its reliability using concordance results between text description and stool drawings among subjects.

In conclusion, this study has revealed that the Spanish version of the Bristol Scale Stool Form is sufficiently reliable to be used as a tool to evaluate stool consistency and form even though individuals with no university degree may have some difficulties in understanding the scale.

\section{ACKNOWLEDGEMENTS}

We would like to thank Professor Heaton at the University of Bristol for his authorization for the translation of this scale, his comments on the design of the study, and his help with the manuscript review. We also thank Omar Faiz and Jose Mullerat for their help in the translation of this scale. Special thanks to Naima Ben Mousa for her help in the management of data.

\section{REFERENCES}

1. Longstreth GF, Thompson WG, Chey WD, Houghton LA, Mearin F, Spiller RC. Functional bowel disorders. Gastroenterology 2006; 130: 1480-91.

2. Tjandra JJ, Dykes SL, Kumar RR, Ellis CN, Gregorcyk SG, Hyman $\mathrm{NH}$, et al. Practice parameters for the treatment of fecal incontinence. Dis Colon Rectum 2007; 50: 1497-507.

3. Davies GJ, Crowder M, Reid B, Dickerson JW. Bowel function measurements of individuals with different eating patterns. Gut 1986; 27 : 164-9.

4. Heaton KW, Thompson WG. Diagnosis. In: Heaton KW, Thompson WG, editors. Iritable bowel syndrome. Oxford: Health Press; 1999. p. 27

5. Heaton KW, Ghosh S, Braddon FE. How bad are the symptoms and bowel dysfunction of patients with the irritable bowel syndrome? A prospective, controlled study with emphasis on stool form. Gut 1991; 32: 73-9.

6. Degen LP, Phillips SF. How well does stool form reflect colonic transit? Gut 1996; 39: 109-13.

7. http://www.familydoctor.co.uk/htdocs/BOWELS/BOWELS_specimen.html.

8. Young AE, Fine PM, McCrery R, Wren PA, Richter HE, Brubaker L, et al. Spanish language translation of pelvic floor disorders instruments. Int Urogynecol J Pelvic Floor Dysfunct 2007; 18: 1171-8.

9. Fleiss J. Statistical methods for rates and proportions. 2nd ed. New York: John Wiley \& sons; 1981.

10. Remes-Troche JM, Ozturk R, Philips C, Stessman M, Rao SS. Cholestyramine-a useful adjunct for the treatment of patients with fecal incontinence. Int J Colorectal Dis 2008; 23: 189-94.

11. Riegler G, Esposito I. Bristol scale stool form. A still valid help in medical practice and clinical research. Tech Coloproctol 2001; 5: 163-4. 
12. Macmillan AK, Merrie AE, Marshall RJ, Parry BR. Design and validation of a comprehensive fecal incontinence questionnaire. Dis Colon Rectum 2008.

13. Heaton KW, Radvan J, Cripps H, Mountford RA, Braddon FE, Hughes AO. Defecation frequency and timing, and stool form in the general population: a prospective study. Gut 1992; 33: 818-24.

14. Giralt J, Regadera JP, Verges R, Romero J, de la Fuente I, Biete A, et al. Effects of probiotic Lactobacillus Casei DN-114 001 in prevention of radiation-induced diarrhea: results from multicenter, randomized, placebo-controlled nutritional trial. Int J Radiat Oncol Biol Phys 2008.

15. Heaton KW, O'Donnell LJ. An office guide to whole-gut transit time. Patients' recollection of their stool form. J Clin Gastroenterol 1994; 19: 28-30.

16. Lewis SJ, Heaton KW. Stool form scale as a useful guide to intestinal transit time. Scand J Gastroenterol 1997; 32: 920-4.

17. Spathis A, Heaton KW, Emmett PM, Norboo T, Hunt L. Gallstones in a community free of obesity but prone to slow intestinal transit. Eur J Gastroenterol Hepatol 1997; 9: 201-6.
18. Aichbichler BW, Wenzl HH, Santa Ana CA, Porter JL, Schiller LR, Fordtran JS. A comparison of stool characteristics from normal and constipated people. Dig Dis Sci 1998; 43: 2353-62.

19. Hearing SD, Thomas LA, Heaton KW, Hunt L. Effect of cholecystectomy on bowel function: a prospective, controlled study. Gut 1999; 45: 889-94.

20. Ferrazzi S, Thompson GW, Irvine EJ, Pare P, Rance L. Diagnosis of constipation in family practice. Can J Gastroenterol 2002; 16: 15964.

21. Yilmaz S, Dursun M, Ertem M, Canoruc F, Turhanoglu A. The epidemiological aspects of irritable bowel syndrome in Southeastern Anatolia: a stratified randomised community-based study. Int J Clin Pract 2005; 59: 361-9.

22. Adibi P, Behzad E, Pirzadeh S, Mohseni M. Bowel habit reference values and abnormalities in young Iranian healthy adults. Dig Dis Sci 2007; 52: 1810-3.

23. Choung RS, Locke GR, 3rd, Zinsmeister AR, Schleck CD, Talley NJ Epidemiology of slow and fast colonic transit using a scale of stool form in a community. Aliment Pharmacol Ther 2007; 26: 1043-50. 